\title{
ROSTER OF AFFILIATES GROWS
}

\section{A Dozen Concerns Are Added As MRS Corporate Affliates, Making The Current List The Largest In The Society's History}

Another dozen institutions have joined with the Materials Research Society in accelerating the pace of materials research and development and improving their quality as MRS Corporate Affiliates. The new Affiliates are Applied Materials; ARCO/Solar, Inc.; C-E Power Systems; Drytek, Inc.; Energy Conversion Devices, Inc.; GCA Corporation; Instruments SA, Inc.; LFE Corporation; Los Alamos National Laboratory; Materials Research Corporation; Plasma-Therm Systems, Inc., and Solarex.

"The addition of these new Affiliates brings our roster of corporate supporters to some 65 , the largest number in the Society's history," reports C.W. (Clif) Draper, AT\&T Technologies, Inc., Chairman of the Society's Corporate Participation Committee.

\section{Fulfilling its Objective}

"The growth of participants in our program of corporate sponsorship demonstrates concretely that the Society is fulfilling its primary objective-serving professionals in the field of materials science and engineering," says Clif.

"This growth also is a tribute to the hard work performed by our

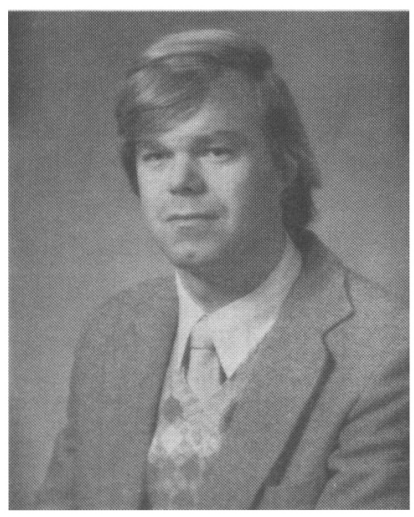
Committee," he adds. "But it

\section{CLIF DRAPER}

is due as well to increasing participation in this effort by others in the Society. Our members are becoming our most valuable advocates with corporations and laboratories that are potential Affiliates."

\section{Member Support Vital}

Clif stresses: "The active support of MRS members is vital to the continuing growth of this activity. I would urge all members to contact me with suggested Affiliates. Working with you, we can explain the many benefits of the program fully, and demonstrate why participation strengthens our Society, our profession, and our corporate sector." Members can reach Clif at AT\&T Technologies' Engineering Research Center in Princeton, N.J. His number is (609) 639-2350.

Clif notes that MRS Corporate Affiliates receive a number of benefits, including literature displays without charge at MRS meetings, announcements in the BULLETIN, a complimentary subscription to the MRS-affiliated letters journal, Materials Letters, and various forms of recognition. "We also benefit from suggestions by Corporate Affiliates about topics for possible future symposia," he adds.

\section{Roster of Affiliates}

The current roster of the Materials Research Society's Corporate Affiliates includes the following:

Air Products and Chemicals Allied Corporation Aluminum Company of America Applied Materials ARCO/Solar, Inc.
AT\& T Technologies (The Engineering Research Center) Branson, IPC

Brimrose Corporation of America

C-E Power Systems

Chevron

Coherent

Drytek, Inc.

E.I. DuPont de Nemours \& Company Eastman Kodak Company

Eaton Corporation

EG\&G ORTEC

Elborg Technology Company

Elsevier North-Holland

Energy Conversion Devices, Inc.

Exxon Research and Engineering Company GCA Corporation

General Electric Company

General Ionex Corporation

General Motors Research Laboratories

GTE Laboratories

Harshaw/Filtrol

Helionetics

Hitachi Scientific Instruments

Instruments SA, Inc.

International Business Machines Corporation Jeol USA

Lam Research

Lambda Physik

[Continued on Page 17] 


\section{AMORPHOUS METALS}

\section{An MRS-Europe Symposium Report}

The symposium entitled "Amorphous Metals and Nonequilibrium Processing" was devoted to the connections between various approaches to amorphization of metals, ranging from traditional techniques, such as melt spinning and vapor quenching, to laser irradiation, and from ionbeam mixing to solid-state reaction. Three of the six oral sessions focused on the processes, while the other three concentrated on the properties of amorphous phases as produced by the various processes. In all, the program comprised 49 scientific papers.

A.R. Yavari opened the first session with a survey of the basic kinetic considerations to predict glass formation or crystallization in melt quenching. A number of speakers then discussed technical aspects of melt spinning as well as scanned $\mathrm{CW}$-Laser irradiation, two techniques that yield cooling rates up to about $10^{6} \mathrm{~K} / \mathrm{sec}$.

The second day was opened by an excellent plenary talk by H.K.J. Buschow discussing magnetic and electronic properties and showing perspectives on applications of amorphous metals in data recording and storage. The tone for the session on ion beams and chemical processes was set by M.A. Nicolet with a talk on what is and what isn't presently understood about amorphization by ion beams. Exciting new experiments on the amorphization by solidstate reactions were reported by two speakers later in the session. The process is carried out at a temperature too low for crystallization but sufficient for fast diffusion by one of the component species, and promises the production of amorphous alloys of almost arbitrary dimensions. The last session on processes was devoted to ultra-rapid quenching and nanosecond or picosecond laser quenching. Both methods yield cooling rates in excess of $10^{10} \mathrm{~K} / \mathrm{sec}$ and offer a wide range of amorphous alloys, but are basically limited to thin films.

The sessions devoted to properties treated the subjects of crystallization, lowtemperature properties, and atomic and electronic structures of amorphous metals. Among the highlights were talks on the micromechanisms of crystallization in glassy metals, as compared with those in amorphous

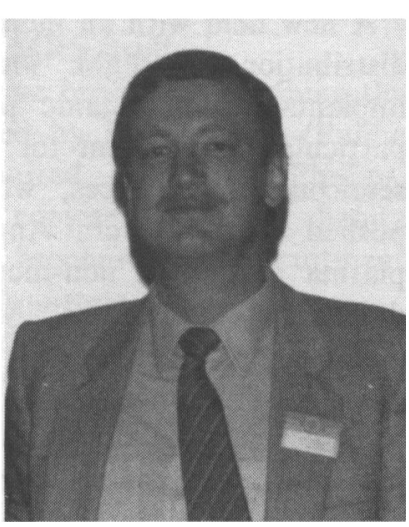

M. VON ALLMEN semiconductors, and on properties of amorphous metals at very high pressure. A poster session complemented the scientific program of the symposium.

\section{M. von Allmen}

Berne, Switzerland

\section{AFFILIATES}

[Continued from Page 10]

Lawrence Livermore National Laboratory LFE Corporation

Los Alamos National Laboratory Lumonics

Martin Marietta Laboratories

Materials Research Corporation

Microscience, Inc.

Monsanto

Perkin-Elmer

Philips Electronic Instruments, Inc.

Portland Cement Association

Plasma-Therm Systems, Inc.

Quantronix Corporation

Questek, Inc.

Sandia National Laboratories
Schlumberger-Doll Research

Shell Development Company

Solarex

Spectra Physics

Spire Corporation

Standard Oil Company of Indiana

TRW

Tegal Corporation

Union Carbide Corporation

United Technologies Research Center

UOP

Varian/Extrion

W.R. Grace \& Company

Westinghouse Electric Corporation

Xerox Corporation

XMR

Zymet 